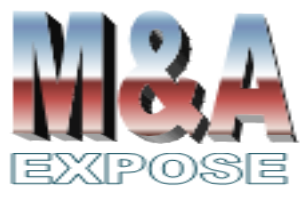

http://jurnal.usahid.ac.id/index .php/accounting
${ }^{1}$ Fakultas Ekonomi dan Bisnis Universitas Sahid ina diamhur@usahid.ac.id

\section{Kesenjangan Expected Service dan Perceived Service dalam Service Quality di Stasiun Commuter Line Jakarta}

\author{
Mesel Ghea Hilyati Nisrin ${ }^{1}$, Ina Gandawati Djamhur ${ }^{1}$
}

\section{Abstrak}

Terdapat permasalahan ketidaksesuaian harapan dan persepsi penumpang terhadap pelayanan petugas tiket PT Kereta Commuter Indonesia (KCl) pada Commuter Vending Machine (CVIM) khususnya di wilayah Jakarta. Penumpang mempersepsikan petugas tiket belum memberikan pelayanan yang baik seperti yang tertera dalam nilai budaya pelayanan prima. Penelitian ini bertujuan menganalisis harapan dan persepsi penumpang terhadap pelayanan petugas. Penelitian ini merupakan penelitian kuantitatif, menggunakan pendekatan komparatif antara harapan dan persepsi. Hasil penelitian menunjukkan nilai harapan lebih besar daripada nilai persepsi. $\mathrm{KCl}$ perlu melakukan evaluasi secara berkala terhadap pelayanan petugas tiket terutama di stasiun Jakarta Kota yang memiliki nilai ketidaksesuaian cukup tinggi. Petugas tiket harus meningkatkan kemampuannya, baik dalam berkomunikasi maupun penyampaian pelayanan kepada penumpang.

Kata kunci : Harapan, Persepsi, Kualitas Pelayanan.

\section{Abstract}

There are still problems in the discrepancy between the expectations and perceptions of passengers, towards the service of PT Kereta Commuter Indonesia (KCl) ticket officers in the Commuter Vending Machine (C-VIM), especially in the Jakarta area. Passengers perceive that ticket officers have not been able to provide good service as stated in the value of excellent service culture. This study analyze the expectations and perceptions of passengers towards the service of officers. This research is a quantitative study, using a comparative approach between expectations and perceptions. The results showed the value of expectations is greater than the value of perception. $\mathrm{KCl}$ needs to conduct periodic evaluations of ticket attendant services, especially in Jakarta Kota stations which have a high value of nonconformities. Ticket officers must improve their abilities, both in communicating and delivering services to passengers.

Keywords: Expectation, Perception, Service Quality. 


\section{PENDAHULUAN}

Kota Jakarta sebagai kota metropolitan yang menjadi pusat pemerintahan dan pusat aktivitas ekonomi memiliki mobilitas tenaga kerja baik dari dalam kota Jakarta itu sendiri, maupun dari luar Jakarta seperti Bogor, Depok, Tangerang dan Bekasi. Salah satu transportasi publik yang digunakan untuk akses ke tempat kerja adalah moda kereta rel listrik (KRL) yang dikelola oleh PT. Kereta Commuter Indonesia (KCl). Jumlah penumpang yang diangkut oleh $\mathrm{KCl}$ setiap tahunnya mengalami peningkatan sebagaimana tertera pada Tabel 1 berkut.

Tabel 1. Jumlah Penumpang KRL Tahun 2013-2018

\begin{tabular}{ccc}
\hline Tahun & Jumlah (Dalam Juta Orang) & Pertumbuhan \\
\hline 2013 & 158.5 & \\
2014 & 208.5 & $31.5 \%$ \\
2015 & 257.5 & $23.5 \%$ \\
2016 & 280.6 & $8.9 \%$ \\
2017 & 315.8 & $12.5 \%$ \\
\hline \multicolumn{3}{c}{}
\end{tabular}

Sumber : databoks.co.id (24 Juli 2018)

Berdasarkan Laporan Tahunan PT KCI (2017), jumlah penumpang yang diangkut sebanyak 315.853.991 orang atau tumbuh sebanyak 12.57 persen dari tahun 2016. Hingga bulan Juni 2018, rata-rata jumlah pengguna KRL per hari mencapai 1.001 .438 pengguna pada hari kerja, dengan rekor jumlah pengguna terbanyak yang dilayani dalam satu hari adalah 1.154.080. Bahkan menurut Deputi II PT KAI Daerah Operasi I Jakarta, Junaidi Nasution, kini jumlah penumpang KRL di Jabodetabek mencapai 1,1 juta orang per hari. Jika diasumsikan tarif terendah senilai Rp3.000, setiap harinya jumlah transaksi tiket KRL mencapai Rp 3,3 miliar (merdeka.com, tanggal 3 April 2019). Pada tahun 2019 ini dengan mengusung semangat dan semboyan Best Choice for Urban Transport, $\mathrm{KCl}$ saat ini terus bekerja keras untuk memenuhi target melayani 1,2 juta penumpang per hari dengan kekuatan armada KRL hingga 1.450 unit melayani 79 stasiun di seluruh Jabodetabek, Banten dan Cikarang dengan jangkauan rute mencapai 418,5 km.

Seiring pertumbuhan tersebut, $\mathrm{KCl}$ memperluas rentang pelayanan, melakukan berbagai inovasi serta modernisasi layanan. Inovasi dan modernisasi yang dilakukan terutama berfokus pada upaya perbaikan fasilitas pelayanan, konektivitas antarmoda angkutan dan keselamatan pengguna. Terkait inovasi layanan, pada awal $2018 \mathrm{KCl}$ telah mengoperasikan 236 unit commuter vending machine dan 749 gate elektronik yang tersebar di 79 stasiun untuk meningkatkan kemudahan layanan kepada pengguna. Masih terkait dengan modernisasi pelayanan, sejak $2013 \mathrm{KCl}$ telah menerapkan sistem tiket elektronik (eTicketing) dan sistem tarif progresif. Penerapan e-ticketing mendorong peningkatan minat masyarakat menggunakan moda transportasi $\mathrm{KCl}$. Penerapan sistem e-Ticketing, menggantikan tiket kertas menjadi dua jenis elektrik (Smart Card) yaitu Kartu Single Trip (KST) yaitu tiket elektronik yang digunakan untuk satu kali perjalanan KRL pada hari pembelian, dan Kartu Multi Trip (KMT) adalah tiket elektronik yang digunakan dengan sistem saldo mengendap sebesar maksimal Rp. 1 juta. Selain itu dilakukan penerapan Tiket Harian Berjamin (THB) dengan uang jaminan sebesar Rp. 5.000 untuk menggantikan Tiket Single 
Trip, jaminan dapat diambil kembali di loket $\mathrm{KCl}$ dalam tujuh hari. Penumpang tidak perlu ke loket untuk membeli tiket. Hanya perlu tap in di gerbang stasiun keberangkatan dan tap out di gerbang stasiun kedatangan, maka saldo akan berkurang sesuai tarif yang dihitung otomatis. Berikut data jumlah penumpang yang memiliki THB dan KTM di tahun 2018.

Tabel 2. Jumlah Penumpang Pengguna THB dan KMT pada tahun 2018

\begin{tabular}{ccccc}
\hline Bulan & THB & KMT & Total & Peningkatan \\
\hline Januari & 10.066 .872 & 9.368 .238 & 19.435 .110 & - \\
Februari & 9.110 .702 & 9.232 .830 & 18.343 .532 & $-5,6 \%$ \\
Maret & 9.761 .222 & 10.173 .435 & 19.934 .657 & $8,7 \%$ \\
April & 9.672 .359 & 10.157 .613 & 19.829 .972 & $-0,5 \%$ \\
Mei & 11.025 .192 & 10.013 .004 & 21.038 .196 & $6,1 \%$ \\
Juni & 10.105 .134 & 10.218 .186 & 20.323 .320 & $-3,4 \%$ \\
Juli & 10.884 .449 & 7.854 .306 & 18.738 .755 & $-7,8 \%$ \\
Agustus & 9.607 .048 & 10.450 .229 & 20.057 .277 & $7,0 \%$ \\
September & 9.481 .683 & 10.236 .260 & 19.717 .943 & $-1,7 \%$ \\
Oktober & 9.812 .711 & 10.715 .252 & 20.527 .963 & $4,1 \%$ \\
November & 9.258 .041 & 10.812 .772 & 20.070 .813 & $-2,2 \%$ \\
Desember & 10.917 .523 & 10.105 .237 & 21.022 .760 & $4,7 \%$ \\
\hline & 119.702 .936 & 119.337 .362 & 239.040 .298 & $0,5 \%$ \\
\hline
\end{tabular}

Sumber : Dokumen pribadi Humas PT. KCl.

Tabel 3. Stasiun Terpadat di Jakarta pada Tahun 2018

\begin{tabular}{|c|c|c|c|c|c|c|c|c|}
\hline \multirow[b]{2}{*}{ No } & \multirow[b]{2}{*}{ Stasiun } & \multirow[b]{2}{*}{$\begin{array}{l}\text { Orang } \\
\text { /hari }\end{array}$} & \multicolumn{4}{|c|}{ C-VIM } & \multicolumn{2}{|c|}{ Loket } \\
\hline & & & Umum & KMT & $\begin{array}{c}\text { Petugas } \\
\text { /Shift }\end{array}$ & Status & Unit & $\begin{array}{c}\text { Petugas } \\
\text { /Shift }\end{array}$ \\
\hline 1. & Tanah Abang & 1.334 .243 & - & 2 & - & - & 4 & 4 \\
\hline 2. & Sudirman & 821.057 & 4 & 2 & 1 & Aktif & 2 & 2 \\
\hline 3. & Tebet & 754.998 & 4 & 2 & - & - & 2 & 2 \\
\hline 4. & Jakarta Kota & 733.311 & 9 & 4 & 2 & Aktif & 2 & 2 \\
\hline 5. & Gondangdia & 553.622 & 2 & 4 & 1 & Aktif & 2 & 2 \\
\hline 6. & Pasar Minggu & 551.488 & 3 & 3 & 1 & Aktif & 2 & 2 \\
\hline 7. & Duren Kalibata & 527.076 & 2 & 2 & 1 & Aktif & 2 & 2 \\
\hline 8. & Manggarai & 511.295 & 3 & 1 & 1 & Aktif & 1 & 1 \\
\hline 9. & Juanda & 443.844 & 2 & 2 & 1 & Aktif & 2 & 2 \\
\hline 10. & Cawang & 438.874 & 2 & 2 & 1 & Aktif & 2 & 2 \\
\hline
\end{tabular}

Sumber : Dokumen pribadi Humas PT. KCl.

Berdasar Tabel 2, total jumlah penumpang yang menggunakan tiket THB maupun KMT sebanyak 239.040.298 orang, sementara total jumlah penumpang $\mathrm{KCl}$ berjumlah 280.588.766, atau naik sekitar 85.16 persen. Tingginya minat penumpang untuk menggunakan $\mathrm{KRL}$ dapat dilihat dari antrean panjang di loket tiket. Solusi $\mathrm{KCl}$ untuk mengurangi antrean panjang dengan mengembangkan dan menyediakan mesin penjualan tiket atau Commuter Vending Machine (C-VIM) dengan layar sentuh, yang berfungsi sebagai transaksi THB (sales, resales, dan refund) dan top up KMT. Setelah hadirnya C-VIM, maka loket konvensional di stasiun-stasiun prioritas akan ditiadakan karena fungsinya sudah digantikan dengan mesin tiket. Pawal 2018 terdapat 236 vending machine yang tersebar di 
79 stasiun terpadat di wilayah Jakarta, seperti Jakarta Kota, Sudirman, dan Pondok Cina, Tanah Abang, Tebet, dan lain-lain. Agar penumpang dapat melakukan transaksi dengan cepat serta mengurai antrian, maka $\mathrm{PT} \mathrm{KCl}$ menyediakan petugas pelayanan yang berjaga untuk membantu memandu, mengarahkan penumpang melalui C-VIM.

Pada loket manual transaksi dapat dilakukan hanya dalam 30 detik/transaksi, sedangkan waktu yang dibutuhkan untuk satu kali bertransaksi di C-VIM sekitar 1 - 2 menit. Petugas tiket memiliki peranan penting dalam membantu memperkenalkan C-VIM kepada penumpang. Namun masih banyak penumpang belum mampu menggunakan C-VIM secara mandiri dan memerlukan pendampingan petugas tiket, misalnya membantu proses transaksi. Dampaknya para petugas tiket merasa kewalahan dalam menjalankan tugasnya melayani permintaan penumpang dikarenakan keterbatasan jumlahnya. Kendala dan permasalahan lainnya adalah petugas tiket kurang memiliki kemampuan berkomunikasi efektif kepada penumpang, dan attitude atau perilaku petugas yang kurang sopan, dan standar operating procedure yang belum jelas sehingga pelayanan kurang maksimal. Sesungguhnya harapan penumpang adalah menginginkan pelayanan yang sesuai nilai utama budaya $\mathrm{KCl}$ yaitu integritas, profesional, keselamatan, inovasi dan pelayanan prima. Pelayanan petugas tiket merupakan bagian penting dari nilai utama budaya $\mathrm{KCl}$ merujuk pada pelayanan prima. Nilai budaya $\mathrm{PT}$. $\mathrm{KCl}$ adalah memberikan pelayanan yang terbaik yang sesuai dengan standar mutu yang memuaskan dan sesuai harapan atau melebihi harapan pelanggan dengan memenuhi 6A unsur pokok, yaitu Ability (Kemampuan), Attitude (Sikap), Appearance (Penampilan), Attention (Perhatian), Action (Tindakan), dan Accountability (Tanggung jawab). Berarti masih terdapat gap/kesenjangan pelayanan antara harapan dan persepsi karena petugas tiket belum mampu menerapkan filosofi pelayanan dan budaya perusahaan yang telah dicanangkan.

Penelitian ini bertujuan menganalisis gap antara harapan dan persepsi penumpang terhadap pelayanan petugas tiket pada C-VIM di stasiun wilayah Jakarta. Hasil dari pengujian ini berguna sebagai ukuran pelayanan petugas tiket dalam memenuhi nilai pelayanan prima $\mathrm{PT}$. $\mathrm{KCl}$.

\section{TINJAUAN PUSTAKA}

Kualitas Pelayanan. Goetsch dan Davis dalam Tjiptono \& Chandra (2016) menyatakan bahwa kualitas sebagai kondisi dinamis yang berhubungan dengan produk, jasa, sumber daya manusia, proses dan lingkungan yang memenuhi atau melebihi harapan. Lewis dan Booms dalam Tjiptono dan Chandra (2016) mendefinisikan kualitas jasa sebagai ukuran seberapa bagus tingkat pelayanan sesuai ekspektasi pelanggan. Berdasarkan definisi ini, kualitas jasa dapat diwujudkan melalui pemenuhan kebutuhan dan keinginan pelanggan serta ketepatan penyampaiannya untuk mengimbangi harapan pelanggan.

Parasuman dalam Tjiptono dan Chandra (2016) menyebutkan dua faktor utama yang mempengaruhi kualitas jasa, yaitu expected service dan perceived service. Apabila jasa yang dirasakan (perceived service) sesuai dengan jasa yang diharapkan (expected service), maka kualitas jasa yang bersangkutan akan dipersepsikan baik atau positif. Jika perceived service melebihi expected service, maka kualitas jasa dipersepsikan sebagai kualitas ideal. Sebaliknya jika perceived service kurang dari expected service, maka kualitas jasa dipersepsikan buruk atau negatif. 
Persepsi Terhadap Kualitas Jasa. Kotler dan Koller (2012) menyatakan bahwa nilai persepsi konsumen adalah perbedaan antara evaluasi dari sudut pandang konsumen dari semua keuntungan, semua harga yang ditawarkan dan persepsi alternatif. Kualitas jasa harus dimulai dari kebutuhan pelanggan dan berakhir dengan kepuasan pelanggan serta persepsi positif terhadap kualitas jasa.

Schiffman dan Kanuk (2008) menyatakan bahwa persepsi didefinisikan sebagai proses yang dilakukan individu untuk memilih, mengatur, dan menafsirkan stimuli ke dalam gambar yang berarti dan masuk akal mengenai dunia. Tjiptono dan Chandra (2016) menyatakan persepsi secara relatif seragam sebagai keyakinan mengenai jasa yang dialami. Keyakinan menyangkut atribut produk, tingkat atribut, atau hasil yang diterima. Schiffman dan Kanuk (2008) menyatakan empat konsep dasar yang mendasari proses memperoleh persepsi yaitu :

1. Sensasi, merupakan responsi langsung dari alat pancaindra terhadap stimuli yang sederhana (iklan, kemasan, merek).

2. Ambang Absolut, merupakan tingkat terendah ketika seseorang dapat mengalami sensasi. Titik di mana orang merasakan antara ada sesuatu dan tidak ada apa-apa. Dua orang yang berkendara bersama melihat billboard di jalan raya.

3. Ambang Diferensial, merupakan perbedaan minimal yang dapat dirasakan antara dua macam stimuli yang hampir serupa. Contohnya, jika harga mobil mengalami kenaikan satu juta rupiah, mungkin tidak akan diperhatikan. Mungkin diperlukan kenaikan dua juta rupiah atau lebih untuk menjadi perbedaan harga menjadi perhatian.

4. Persepsi Sublimasi, merupakan stimuli yang terlau lemah atau terlalu singkat untuk melihat atau terdengar secara sadar atau mungkin terlalu kuat untuk dapat disadari oleh satu sel atau lebih penerima.

Schiffman dan Kanuk (2008) menyatakan bahwa secara tidak sadar para konsumen banyak menggunakan kemampuan mereka dalam memilih aspek faktor stimuli mana yang mereka terima, yaitu :

1. Pengalaman Konsumen sebelumnya faktor ini mempengaruhi harapan-harapan konsumen. Dalam konteks pemasaran orang cenderung merasakan produk dan sifatsifat produk berdasarkan harapan-harapan mereka sendiri

2. Motif mereka pada satu waktu Orang cenderung memperhatikan hal-hal yang mereka butuhkan atau inginkan semakin kuat kebutuhan tersebut semakin kuat kecenderungan untuk mengabaikan stimuli yang tidak ada hubungannya

Harapan Konsumen. Menurut Oslon dan Dover dalam Tjiptono dan Chandra (2016) menyatakan bahwa harapan atau ekspektasi konsumen merupakan keyakinan pelanggan sebelum mencoba atau membeli suatu produk, yang dijadikan standar atau acuan dalam menilai kinerja produk yang bersangkutan. Santos dan Boote dalam Tjiptono dan Chandra (2016) mengklarifikasikan sebuah hierarki harapan konsumen ke dalam sembilan kelompok sebagai berikut :

1. Harapan ideal, yaitu tingkat kinerja optimum atau terbaik yang diharapkan dapat diterima konsumen.

2. Harapan normatif, yaitu tingkat kinerja yang dirasakan konsumen, seharusnya mereka dapatkan dari produk atau jasa.

3. Harapan yang diinginkan, yaitu tingkat kinerja yang diinginkan pelanggan dapat diberikan produk atau jasa tertentu. 
4. Harapan yang diperkirakan, yaitu tingkat kinerja yang diantisipasi atau diperkirakan konsumen akan diterima, berdasarkan semua informasi yang diketahui.

5. Harapan yang pantas, yaitu evaluasi subjektif konsumen terhadap investasi produknya. Tipe harapan ini berkenan dengan apa yang setidaknya harus terjadi pada interaksi.

6. Harapan yang cukup, yaitu tingkat harapan batas bawah dalam ambang batas kinerja produk atau jasa yang diterima pelanggan.

7. Harapan dengan toleransi rendah, yaitu tingkat toleransi terendah yang bisa diterima atau ditolerir konsumen.

8. Harapan tanpa toleransi, yaitu serangkaian harapan menyangkut tingkat kinerja yang tidak dapat diterima pelanggan.

9. Harapan yang terburuk dari perkiraan, yaitu skenario terburuk mengenai kinerja produk yang diketahui dan terbentuk melalui kontak dengan media, seperti TV, radio, koran atau internet.

Zeithaml, Parasuraman dan Berry dalam Tjiptono dan Chandra (2016) mengemukakan model konseptual harapan konsumen terhadap jasa yang mengidentifikasi sepuluh faktor utama harapan konsumen, sebagai berikut :

1. Enduring service intensifiers merupakan faktor yang bersifat stabil dan mendorong pelanggan untuk meningkatkan sensitivitas-nya terhadap jasa. Faktor ini meliputi harapan yang dipengaruhi orang lain dan filosofi pribadi seseorang tentang jasa

2. Personal need merupakan kebutuhan yang dirasakan seseorang mendasar bagi kesejahteraannya juga sangat menentukan harapannya. Kebutuhan personal meliputi kebutuhan fisik, sosial, dan psikologis

3. Transitory service intensifiers merupakan faktor individual yang bersifat sementara yang meningkatkan sensitivitas pelanggan terhadap jasa. Faktor ini meliputi situasi darurat pada saat konsumen membutuhkan jasa, juga pada saat jasa terakhir yang dikonsumsikan konsumen

4. Perceived service alternatives merupakan persepsi pelanggan terhadap tingkat layanan perusahaan lain sejenis

5. Self-perceived service roles, yaitu mencerminkan persepsi pelanggan terhadap tingkat keterlibatannya dalam mempengaruhi jasa yang diterimanya

6. Situational factors terdiri atas segala kemungkinan yang bisa mempengaruhi kinerja jasa, yang berada di luar kendali penyedia jasa

7. Explicit service promises merupakan pernyataan atau janji organisasi tentang jasanya kepada para pelanggan. Janji ini bisa berupa personal selling, perjanjian atau komunikasi dengan karyawan organisasi tersebut

8. Implicit service promises adalah menyangkut petunjuk berkaitan dengan jasa, yang memberikan kesimpulan atau gambaran bagi pelanggan tentang jasa seperti apa yang seharusnya dan yang akan diterima

9. Word of mouth merupakan pernyataan langsung ataupun tidak langsung yang disampaikan oleh orang lain selain organisasi penyedia jasa kepada pelanggan.

10. Past experiences yaitu pengalaman masa lampau meliputi hal-hal yang telah dipelajari atau diketahui pelanggan dari yang pernah diterima di masa lalu.

Unsur Kualitas Pelayanan. Parasuraman, Berry dan Zeithaml dalam Kotler dan Koller (2012) mengidentifikasi terdapat lima atribut atau unsur kualitas pelayanan yang biasa dikenal dengan istilah kualitas layanan "RATER" (reliability, assurance, tangible, empathy dan responsiveness), yaitu : 
1. Reliability (kehandalan) yaitu kemampuan untuk melakukan pelayanan yang dijanjikan secara andal dan akurat. Komponen yang menyangkut atribut ini meliputi penyediaan jasa sesuai yang dijanjikan, dapat diandalkan dalam menangani masalah jasa pelanggan, menyampaikan jasa secara benar, menyampaikan jasa sesuai dengan waktu yang dijanjikan, menyimpan catatan dan dokumen tanpa kesalahan.

2. Assurance (jaminan) adalah pengetahuan, kesopanan, dan kemampuan karyawan untuk menyampaikan kepercayaan konsumen dan korporat. Karyawan yang menumbuhkan rasa percaya pada pelanggan, membuat pelanggan merasa aman sewaktu melakukan transaksi. Karyawan secara konsisten bersikap sopan, dan mampu menjawab pertanyaan pelanggan.

3. Tangible (bukti fisik) berupa kondisi fasilitas fisik, peralatan, personalia, dan komunikasi jasa dan produk. Komponen ini mencakup aspek peralatan, fasilitas, kerapihan penampilan karyawan, dan suasana kantor.

4. Empathy (empati) yaitu pemberian kepedulian, perhatian individual terhadap pelanggan. Komponen atribut ini meliputi pemberikan perhatian individual kepada para pelanggan, memperlakukan pelanggan secara penuh perhatian, mengutamakan kebutuhan dan kepentingan pelanggan, waktu beroperasi yang nyaman dan fleksibel.

5. Responsiveness (daya tanggap) yaitu kesediaan untuk membantu pelanggan dan memberikan pelayanan yang cepat. Komponen ini meliputi menginformasikan pelanggantentang kepastian waktu penyampaian jasa, layanan yang segera atau cepat bagi pelanggan, dan kesediaan untuk membantu pelanggan.

\section{METODE PENELITIAN}

Variabel Penelitian. Variabel-variabel penelitian yang digunakan untuk mengukur pelayanan petugas tiket $\mathrm{KCl}$ adalah konversi dimensi kualitas pelayanan dari Parasuraman, Berry dan Zeithaml dalam Kotler dan Koller (2012) dengan konsep pelayanan prima PT. $\mathrm{KCl}$.

Tabel 4. Variabel Operasional Penelitian

\begin{tabular}{|c|c|c|c|}
\hline \multicolumn{2}{|c|}{ Dimensi } & \multirow{2}{*}{\multicolumn{2}{|c|}{ Indikator }} \\
\hline $\begin{array}{l}\text { Service Quality } \\
\text { (SERVQUAL) }\end{array}$ & $\begin{array}{c}\text { Pelayanan } \\
\text { Prima PT KCl }\end{array}$ & & \\
\hline \multirow{3}{*}{ Reliabilitas } & \multirow{3}{*}{ Ability } & 1 & $\begin{array}{c}\text { Petugas memperkenalkan cara bertransaksi di C- VIM } \\
\text { dengan benar }\end{array}$ \\
\hline & & 2 & Petugas memiliki kemampuan komunikasi yang baik \\
\hline & & 3 & Petugas selalu stand by di samping C-VIM \\
\hline \multirow{5}{*}{ Daya Tanggap } & \multirow{5}{*}{ Attitude } & 4 & $\begin{array}{c}\text { Petugas tidak pernah menolak apabila diminta bantuan } \\
\text { pengarahan transaksi di C-VIM }\end{array}$ \\
\hline & & 5 & $\begin{array}{l}5 \text { Petugas selalu menawarkan bantuan pengarahan } \\
\text { transaksi di C-VIM }\end{array}$ \\
\hline & & 6 & $\begin{array}{l}\text { Petugas selalu menawarkan bantuan pengarahan } \\
\text { transaksi di C-VIM }\end{array}$ \\
\hline & & 7 & Petugas dapat mengatur barisan antrean C-VIM \\
\hline & & 8 & $\begin{array}{l}\text { Petugas bersedia menukarkan uang jika uang milik } \\
\text { anda lusuh dan robek ketika bertransaksi }\end{array}$ \\
\hline
\end{tabular}


Kesenjangan Expected Service dan Perceived Service....

Mesel Ghea Hilyati Nisrin, Ina Gandawati Djamhur

\begin{tabular}{|c|c|c|c|}
\hline \multicolumn{2}{|c|}{ Dimensi } & \multirow{2}{*}{\multicolumn{2}{|c|}{ Indikator }} \\
\hline $\begin{array}{l}\text { Service Quality } \\
\text { (SERVQUAL) }\end{array}$ & $\begin{array}{l}\text { Pelayanan } \\
\text { Prima PT KCl }\end{array}$ & & \\
\hline & Action & 9 & $\begin{array}{l}\text { Petugas dapat memberikan pengarahan penggunaan } \\
\text { CVIM dengan cepat }\end{array}$ \\
\hline \multirow{3}{*}{ Jaminan } & \multirow{3}{*}{ Accountability } & 10 & $\begin{array}{c}\text { Petugas dapat dipercaya ketika melakukan penukaran } \\
\text { uang }\end{array}$ \\
\hline & & 11 & $\begin{array}{c}\text { Petugas dapat dipercaya ketika melakukan penggantian } \\
\text { proses transaksi mandiri }\end{array}$ \\
\hline & & 12 & $\begin{array}{c}\text { Petugas dapat dipercaya menangani antrean dengan } \\
\text { baik }\end{array}$ \\
\hline \multirow[b]{3}{*}{ Empati } & \multirow[b]{3}{*}{ Attention } & 13 & Petugas memohon maaf mengalami antrean panjang \\
\hline & & 14 & Petugas bersedia mendengarkan keluhan penumpang \\
\hline & & 15 & Petugas bersedia menangani transaksi yang gagal \\
\hline \multirow{3}{*}{ Bukti Fisik } & \multirow{3}{*}{ Appearance } & 16 & Kebersihan mesin C-VIM \\
\hline & & 17 & Petugas memiliki penampilan yang rapi \\
\hline & & 18 & Mesin C-VIM jarang mengalami kerusakan \\
\hline
\end{tabular}

Teknik Sampling. Populasi yang menjadi dasar pengambilan sampel adalah populasi jumlah penumpang pengguna tiket $\mathrm{KCl}$ tahun 2018. Populasi ini dianggap berstrata secara proporsional. Hal ini dikarenakan sampel diambil dari delapan stasiun yang aktif dalam mengoperasikan C-VIM. Teknik pengambilan sampel yang paling sesuai adalah probability sampling dengan pendekatan proportional sampling. Berikut jumlah populasi yang digunakan dalam penelitian ini.

Tabel 5. Populasi dan Sampel Penelitian

\begin{tabular}{|c|c|c|c|}
\hline No. & Stasiun & Orang/Hari & Sampel/Orang \\
\hline 1. & Sudirman/Dukuh Atas & 821.057 & 20 \\
\hline 2. & Jakarta Kota & 733.311 & 17 \\
\hline 3. & Gondangdia & 553.622 & 13 \\
\hline 4. & Pasar Minggu & 551.488 & 13 \\
\hline 5. & Duren Kalibata & 527.076 & 13 \\
\hline 6. & Manggarai & 511.295 & 13 \\
\hline 7. & Juanda & 443.844 & 11 \\
\hline 8. & Cawang & 438.874 & 10 \\
\hline & Total & 4.141 .693 & 110 \\
\hline
\end{tabular}

Berdasarkan tabel populasi dalam penelitian ini berjumlah 4.141 .693 orang. Ukuran sampel penelitian ini didasarkan pada rumus Slovin dengan tingkat kesalahan 10 persen adalah sebagai berikut :

$$
\mathrm{n}=N 1+(N \times e 2)=4.141 .6931+(4.141 .693 \times 0,102)=100
$$

Namun dalam penelitian ini jumlah sampel menjadi 110 sampel, berdasarkan pembulatan pemilihan sampel berdasarkan proposional masing-masing stasiun.

Sumber Data. Menurut Sujarwerni (2015), sumber data menurut cara memperolehnya, meliputi data primer dan data sekunder. Data primer adalah data yang diperoleh secara langsung dari penumpang $K R L$ di delapan stasiun di Jakarta, dan data sekunder data diperoleh dari Humas PT. KCl. 
Teknik Pengumpulan Data. Menurut Asmani dalam Sujarwerni (2015) terdapat beberapa teknik pengumpulan data penelitian, yang biasa digunakan adalah tes, wawancara, observasi, kuesioner, dan analisis dokumen. Dari beberapa teknik pengumpulan data di atas, dilakukan teknik pengumpulan data dengan menggunakan kuesioner Servqual.

Kuesioner SERVQUAL. Kuesioner yang digunakan adalah kuesioner SERVQUAL dengan skala likert. Skala likert sebagai tolak ukuran variabel (harapan dan persepsi) yang memiliki lima tingkat penilaian, nilai skala satu bernilai paling rendah hingga nilai skala lima bernilai paling tinggi. Total indikator yang dijadikan daftar pernyataan kuesioner adalah sebanyak 18 butir pernyataan. Harapan dan persepsi penumpang dikumpulkan dengan menggunakan kuesioner yang berbentuk bulir pernyataan. Masing-masing pernyataan kepada responden diminta pendapatnya terhadap pelayanan petugas tiket (harapan dan persepsi) dengan memberikan skor sebagai berikut.

Tabel 6. Skala Likert dan Nilai Interpretasi

\begin{tabular}{cccc}
\hline Harapan & Scoring & Rentang Penilaian & Persepsi \\
\hline Sangat Penting & 5 & $4,3-5,0$ & Sangat Baik \\
Penting & 4 & $3,5-4,2$ & Baik \\
Ragu-Ragu & 3 & $2,7-3,4$ & Ragu-Ragu \\
Tidak Penting & 2 & $1,9-2,6$ & Tidak Baik \\
Sangat Tidak Penting & 1 & $1,0-1,8$ & Sangat Tidak Baik \\
\hline
\end{tabular}

Teknik Analisis Data. Berdasarkan Sujarweni (2015:121) analisis data yaitu upaya pengolahan data yang digunakan untuk menjawab rumusan masalah. Analisis data deskriptif digunakan untuk menggambarkan secara rinci harapan dan persepsi penumpang terhadap pelayanan petugas tiket. Selanjutnya dilakukan analisis untuk mengetahui kesesuaian antara harapan dan persepsi penumpang terhadap pelayanan petugas tiket. Alat bantu yang digunakan untuk menguji adalah paired sampel t test.

\section{HASIL DAN PEMBAHASAN}

Analisis Tanggapan Penumpang Berdasarkan Populasi Stasiun. Pada analisis deskriptif ini akan dijelaskan hasil tanggapan harapan penumpang berdasarkan populasi penyebarannya.

1. Harapan Penumpang terhadap Pelayanan Petugas Tiket

Berdasarkan Tabel 7 berikut, tingkat harapan penumpang tertinggi didominasi oleh Stasiun Sudirman, Gondangdia dan Pasar Minggu yang berada pada angka 4,7. Harapan penumpang akan pelayanan petugas tiket di tiga stasiun tersebut cukup tinggi, dikarenakan karakter penumpang yang singgah di stasiun tersebut pada umumnya adalah para pekerja/karyawan yang ingin dilayani secara profesional dan cepat. Stasiun Sudirman dahulu dikenal juga dengan nama Stasiun Dukuh Atas, termasuk stasiun kereta yang paling padat pada jam sibuk karena berada di pusat kota Jakarta. Sebagian besar penumpang pada jam sibuk adalah pekerja/karyawan yang menuju pusat-pusat bisnis dan perkantoran di sekitar Jalan Jendral Sudirman dan Jalan M.H. Thamrin. Para pekerja/karyawan tersebut mayoritas berasal dari daerah pendukung Jakarta seperti Bogor, Depok, Bekasi, Cikarang, 
Serpong, atau Tangerang. Begitupun halnya dengan Stasiun Gondangdia yang berada di kawasan Menteng Jakarta Pusat, merupakan stasiun yang dijadikan tempat pemberhentian bagi para pekerja menuju ke tempat kerjanya di sekitar area pusat. Dua stasiun tersebut memiliki predikat sebagai stasiun ternyaman di Jabodetabek versi Koran Sindo.

Tabel 7. Harapan Penumpang Berdasarkan Populasi Stasiun

\begin{tabular}{|c|c|c|c|c|c|c|c|c|c|c|}
\hline \multirow[t]{2}{*}{ Stasiun } & \multirow[t]{2}{*}{$n$} & \multirow[t]{2}{*}{$\sum P i$} & \multirow[t]{2}{*}{$\sum \mathrm{Wi}$} & \multicolumn{5}{|c|}{$\mathrm{Xi}$} & \multirow{2}{*}{ Ei. Xi } & \multirow{2}{*}{$X p$} \\
\hline & & & & 1 & 2 & 3 & 4 & 5 & & \\
\hline \begin{tabular}{l|l}
1 & Sudirman
\end{tabular} & 20 & 18 & 360 & - & - & 6 & 97 & 257 & 1691 & 4,7 \\
\hline \begin{tabular}{l|l}
2 & Jakarta Kota
\end{tabular} & 17 & 18 & 306 & 2 & 2 & 20 & 65 & 217 & 1411 & 4,6 \\
\hline 3 Gondangdia & 13 & 18 & 234 & - & 1 & 5 & 67 & 161 & 1090 & 4,7 \\
\hline 4 Pasar Minggu & 13 & 18 & 234 & - & - & 4 & 62 & 168 & 1100 & 4,7 \\
\hline 5 Duren Kalibata & 13 & 18 & 234 & - & - & 9 & 74 & 151 & 1078 & 4,6 \\
\hline \begin{tabular}{l|l}
6 & Manggarai
\end{tabular} & 13 & 18 & 234 & - & - & 7 & 72 & 155 & 1084 & 4,6 \\
\hline 7 Juanda & 11 & 18 & 198 & - & - & 13 & 70 & 115 & 894 & 4,5 \\
\hline 8 Cawang & 10 & 18 & 180 & - & - & 10 & 63 & 107 & 1411 & 4,5 \\
\hline
\end{tabular}

Sumber : Data diolah.

Adapun Stasiun Pasar Minggu dengan empat jalur kereta, meski tidak memiliki fasilitas lengkap seperti beberapa stasiun lainnya, namun tetap terpilih sebagai salah satu stasiun ternyaman karena kebersihannya dan ketersediaan ruang peron cukup luas. Di malam hari, stasiun ini juga melengkapi dengan penerangan cukup sehingga calon penumpang merasa aman. Selanjutnya Stasiun Sudirman terletak di area perkantoran yang terdiri dari dua lantai, dan hanya diperuntukkan bagi KA Commuter Jabodetabek. Stasiun ini dilengkapi dengan toilet, eskalator, mushola, minimarket, ATM dan commuter ticket vending machine. Sementara tingkat harapan penumpang terendah tergambar di dua Stasiun yaitu Juanda dan Cawang yang berada pada angka 4,5.

2. Persepsi Penumpang terhadap Pelayanan Petugas Tiket

Sementara itu pelayanan yang diterima (dipersepsikan) oleh penumpang terhadap pelayanan petugas tiket adalah sebagai berikut :

Tabel 8. Persepsi Penumpang Berdasarkan Populasi Stasiun

\begin{tabular}{|c|c|c|c|c|c|c|c|c|c|c|}
\hline \multirow[t]{2}{*}{ Stasiun } & \multirow[t]{2}{*}{$n$} & \multirow[t]{2}{*}{$\sum P i$} & \multirow[t]{2}{*}{$\sum \mathrm{Wi}$} & \multicolumn{5}{|c|}{$\mathrm{Xi}$} & \multirow{2}{*}{$\sum \mathrm{Wi} . \mathrm{Xi}$} & \multirow{2}{*}{$X p$} \\
\hline & & & & 1 & 2 & 3 & 4 & 5 & & \\
\hline \begin{tabular}{l|l}
1 & Sudirman
\end{tabular} & 20 & 18 & 360 & - & 11 & 76 & 101 & 172 & 1514 & 4,2 \\
\hline \begin{tabular}{l|l}
2 & Jakarta Kota
\end{tabular} & 17 & 18 & 306 & 2 & 13 & 65 & 125 & 101 & 1228 & 4,0 \\
\hline \begin{tabular}{l|l}
3 & Gondangdia
\end{tabular} & 13 & 18 & 234 & - & 5 & 35 & 70 & 124 & 1015 & 4,3 \\
\hline \begin{tabular}{l|l} 
& Pasar Minggu
\end{tabular} & 13 & 18 & 234 & - & - & 48 & 71 & 115 & 1003 & 4,3 \\
\hline \begin{tabular}{l|l}
5 & Duren Kalibata \\
\end{tabular} & 13 & 18 & 234 & - & 4 & 64 & 61 & 105 & 969 & 4,1 \\
\hline \begin{tabular}{l|l}
6 & Manggarai
\end{tabular} & 13 & 18 & 234 & - & 7 & 44 & 89 & 94 & 972 & 4,2 \\
\hline 7 Juanda & 11 & 18 & 198 & - & 9 & 45 & 59 & 85 & 814 & 4,1 \\
\hline \begin{tabular}{l|l}
8 & Cawang \\
\end{tabular} & 10 & 18 & 180 & - & 12 & 47 & 52 & 69 & 718 & 4,0 \\
\hline
\end{tabular}

Sumber : Data diolah. 
Berdasarkan Tabel 8 dapat diketahui bahwa tingkat persepsi penumpang tertinggi adalah Stasiun Gondangdia dan Pasar Minggu yang berada pada angka 4,3. Pada tingkat harapan, penumpang yang menggunakan kedua stasiun ini memiliki harapan yang tinggi yaitu 4.7, sementara pelayanan yang didapat di kedua stasiun ini menunjukkan angka yang lebih tinggi dibandingkan dengan stasiun lain. Walaupun angkat persepsi ini belum mendekati angka harapan, namun hasilnya masih dikategorikan lebih baik daripada stasiun lain. Tingkat Persepsi penumpang terendah didominasi oleh Stasiun Jakarta Kota dan Cawang yang berada pada angka 4,0.

Tabel 9. Kesenjangan Pelayanan Petugas Tiket

\begin{tabular}{|c|c|c|c|c|}
\hline \multirow{2}{*}{ Atribut } & \multirow{2}{*}{ Indikator } & \multicolumn{2}{|c|}{ Mean } & \multirow{2}{*}{ Gap } \\
\hline & & $X p$ & $X h$ & \\
\hline \multirow{4}{*}{$\begin{array}{c}\text { Ability } \\
\text { Kemampuan }\end{array}$} & $\begin{array}{l}\text { Petugas memperkenalkan cara bertransaksi di C- VIM } \\
\text { dengan benar }\end{array}$ & 4,0 & 4,7 & $-0,7$ \\
\hline & Petugas memiliki kemampuan komunikasi yang baik & 3,9 & 4,5 & $-0,6$ \\
\hline & Petugas selalu stand by di samping C-VIM & 3,9 & 4,7 & $-0,8$ \\
\hline & Mean Atribut Ability Kemampuan & 3,9 & 4,6 & $-0,7$ \\
\hline \multirow{4}{*}{$\begin{array}{l}\text { Attitude } \\
\text { Sikap }\end{array}$} & $\begin{array}{l}\text { Petugas tidak pernah menolak apabila diminta bantuan } \\
\text { pengarahan transaksi di C-VIM }\end{array}$ & 3,8 & 4,7 & $-0,9$ \\
\hline & $\begin{array}{l}\text { Petugas selalu menawarkan bantuan pengarahan } \\
\text { transaksi di C-VIM }\end{array}$ & 4,4 & 4,6 & $-0,2$ \\
\hline & Petugas mengatur barisan antrean C-VIM dengan sabar & 4,0 & 4,5 & $-0,5$ \\
\hline & Mean Atribut Attitude Sikap & 4,1 & 4,6 & $-0,5$ \\
\hline \multirow{4}{*}{$\begin{array}{l}\text { Action } \\
\text { Tindakan }\end{array}$} & Petugas dapat mengatur barisan antrean C-VIM & 4,1 & 4,6 & $-0,5$ \\
\hline & $\begin{array}{l}\text { Petugas bersedia menukarkan uang jika uang milik } \\
\text { anda lusuh dan robek ketika bertransaksi }\end{array}$ & 4,0 & 4,6 & $-0,6$ \\
\hline & $\begin{array}{l}\text { Petugas dapat memberikan pengarahan penggunaan } \mathrm{C} \text { - } \\
\text { VIM dengan cepat }\end{array}$ & 4,2 & 4,7 & $-0,5$ \\
\hline & Mean Atribut Action Tindakan & 4,1 & 4,6 & $-0,5$ \\
\hline \multirow{4}{*}{$\begin{array}{c}\text { Account- } \\
\text { ability } \\
\text { Tanggung } \\
\text { jawab }\end{array}$} & $\begin{array}{l}\text { Petugas dapat dipercaya ketika melakukan penukaran } \\
\text { uang }\end{array}$ & 4,1 & 4,7 & $-0,6$ \\
\hline & $\begin{array}{l}\text { Petugas dapat dipercaya ketika melakukan penggantian } \\
\text { proses transaksi mandiri }\end{array}$ & 4,1 & 4,6 & $-0,5$ \\
\hline & $\begin{array}{l}\text { Petugas dapat dipercaya menangani antrean dengan } \\
\text { baik }\end{array}$ & 4,1 & 4,6 & $-0,5$ \\
\hline & Mean Atribut Accountability Tanggung jawab & 4,1 & 4,6 & $-0,5$ \\
\hline \multirow{4}{*}{$\begin{array}{l}\text { Attention } \\
\text { Perhatian }\end{array}$} & Petugas memohon maaf mengalami antrean panjang & 4,3 & 4,7 & $-0,4$ \\
\hline & Petugas bersedia mendengarkan keluhan penumpang & 4,1 & 4,5 & $-0,4$ \\
\hline & Petugas bersedia menangani transaksi yang gagal & 4,3 & 4,6 & $-0,3$ \\
\hline & Mean Atribut Attention Perhatian & 4,2 & 4,6 & $-0,4$ \\
\hline \multirow{4}{*}{$\begin{array}{l}\text { Appearance } \\
\text { Penampilan }\end{array}$} & kebersihan mesin C-VIM terjamin & 4,2 & 4,7 & $-0,5$ \\
\hline & $\begin{array}{l}\text { Mesin C- VIM tidak pernah mengalami kegagalan } \\
\text { bertransaksi }\end{array}$ & 4,4 & 4,7 & $-0,3$ \\
\hline & Mesin C-VIM memiliki uang kembalian seri terbaru & 4,5 & 4,8 & $-0,3$ \\
\hline & Mean Atribut Appearance Penampilan & 4,4 & 4,7 & $-0,4$ \\
\hline & Mean Total & 4,1 & 4,6 & $-0,5$ \\
\hline
\end{tabular}

Sumber : Data diolah

Berdasarkan Tabel 9, secara keseluruhan harapan penumpang berada pada tingkat sangat penting dengan nilai rata-rata sebesar 4,6. Penumpang sangat berharap pada penampilan petugas dengan nilai rata-rata sebesar 4,7. Dan tingkat harapan penumpang pada kelima atribut lainnya sama, dengan nilai rata-rata sebesar 4,6. Secara keseluruhan juga persepsi penumpang berada pada tingkat baik dengan nilai rata-rata sebesar 4,1. 
Penumpang mempersepsikan bahwa atribut penampilan paling baik dengan nilai rata-rata sebesar 4,4. Persepsi penumpang paling kecil terdapat pada atribut kemampuan petugas dengan nilai rata-rata sebesar 3,9 . Hal ini menunjukkan bahwa tidak ada kesesuaian antara harapan penumpang dan persepsi penumpang.

\section{KESIMPULAN}

Harapan penumpang terhadap pelayanan petugas berada pada angka 4,6 (sangat penting). Jika dilihat berdasarkan stasiun, harapan penumpang tertinggi terdapat pada Sstasiun Sudirman, Gondangdia dan Pasar Minggu dengan nilai rata-rata 4,7 (sangat penting). Harapan penumpang terendah terdapat pada Stasiun Juanda dan Cawang dengan nilai rata-rata 4,5 (sangat penting). Jika dilihat berdasarkan atribut $6 \mathrm{~A}$, harapan penumpang terhadap seluruh atribut sangat penting, dengan nilai rata-rata 4,6 untuk masing-masing atribut Ability (Kemampuan), Attitude (Sikap), Attention (Perhatian), Action (Tindakan), dan Accountability (Tanggung jawab). Hanya atribut Appearance (Penampilan) yang bernilai 4,7.

Persepsi penumpang terhadap pelayanan petugas berada pada angka 4,1 (baik). Jika dilihat berdasarkan stasiun, persepsi penumpang tertinggi terdapat pada Stasiun Gondangdia dan Pasar Minggu berada dengan nilai rata-rata 4,3 (sangat baik). Persepsi penumpang terendah terdapat pada Stasiun Jakarta Kota dan Cawang dengan nilai ratarata 4,0 (baik). Jika dilihat berdasarkan atribut $6 \mathrm{~A}$ persepsi penumpang tertinggi pada atribut Appearance (Penampilan) dengan nilai rata-rata 4,4 (sangat baik), dan terendah terdapat pada Ability (Kemampuan) dengan angka 3,9 (baik).

Saran yang diberikan berdasarkan kesimpulan penelitian, yaitu : petugas tiket harus meningkatkan kemampuan petugas, baik dalam berkomunikasi ataupun penyampaian pelayanan kepada penumpang. Hal ini dikarenakan ketidaksesuaian tertinggi terjadi pada kemampuan pelayanan petugas.

\section{DAFTAR PUSTAKA}

Khusaini, Ahmad. 2016. Analisis Kualitas Pelayanan Terhadap Kepuasan Konsumen di Spa Club Arena Yogyakarta.

Kotler, P dan Keller, K. 2012. Marketing Management 14Th E. Penerbit Prentice Hall : New Jersey.

Laporan Tahunan PT. Kereta Commuter Indonesia Tahun 2018. A Transformation For Greater Service.

Putri, Lagza Lasita. 2017. Analisa Kesesuaian Harapan dan Persepsi Pengguna (Mahasiswa Sejarah) Mengenai Kualitas Layanan Arsip Berdasarkan Lima Dimensi Kualitas Jasa (Servqual) di Badan Perpustakaan Dan Kearsipan Provinsi Jawa Timur. Jurnal Universitas Airlangga.

Rangkuti, Freddy. 2017. Customer Care Excellence. Penerbit PT. Gramedia Pustaka Utama : Jakarta.

Schiffman, L. dan Kanuk, L. 2008. Perilaku Konsumen. Edisi Ketujuh. Penerbit Indeks : Jakarta. 
Sujarweni, Wiratna. 2015. Metodologi Penelitian Bisnis dan Ekonomi. Penerbit Pustakabaru Press : Yogyakarta.

Tjiptono, F. dan Chandra, G. 2016. Service, Quality dan Satisfaction. Edisi 4. Penerbit Andi :Yogyakarta.

Tjiptono, F. dan Diana, A. 2015. Pelanggan Puas? Tak Cukup!. Penerbit Andi : Yogyakarta. 